University for Business and Technology in Kosovo

UBT Knowledge Center

UBT International Conference

2016 UBT International Conference

Oct 28th, 9:00 AM - Oct 30th, 5:00 PM

\title{
Role of the architects in creating building and urban resilience
}

Ferhat Bejtullahu

University for Business and Technology, ferhat.bejtullahu@ubt-uni.net

Follow this and additional works at: https://knowledgecenter.ubt-uni.net/conference

Part of the Architecture Commons

\section{Recommended Citation}

Bejtullahu, Ferhat, "Role of the architects in creating building and urban resilience" (2016). UBT International Conference. 60.

https://knowledgecenter.ubt-uni.net/conference/2016/all-events/60

This Event is brought to you for free and open access by the Publication and Journals at UBT Knowledge Center. It has been accepted for inclusion in UBT International Conference by an authorized administrator of UBT Knowledge Center. For more information, please contact knowledge.center@ubt-uni.net. 
Book of Proceedings

International Conference on Architecture and Spatial Planning

\title{
Role of the architects in creating building and urban resilience
}

\author{
Ferhat Bejtullahu \\ UBT - Higher Education Institution, Lagjja Kalabria, 10000 p.n., \\ Prishtine, Kosovo \\ ferhat.bejtullahu@ubt-uni.net
}

\begin{abstract}
Extreme weather events are increasing in intensity and frequency. While the social component of resilience with all its dimensions depend on all citizens, spatial and environmental components with all their dimensions depend on more from architects than from other professionals. In this context, architects have a responsibility to evaluate, design (create) and maintain resilient build environment that can more successfully adapt to natural conditions and that can more readily absorb and recover city from different disasters.

The objective of this research and used methodology is to identify the role of architects in creating the building and urban resilience qualities that can be implemented in a variety of contexts at national, regional or global level.

Conclusions serve as a new concept to future researches in this field and to all regional stakeholders engaged in the process of evaluating building natural disaster risks and creating strategies for improvement of building and urban resilience professionally.
\end{abstract}

Keywords: Architects, buildings; climate change; urban resilience

\section{Introduction}

Today buildings and cities are under pressure of destructive forces coming from the fire, storms, earthquakes, flooding, and even intentional attack-war. Architecture, which in the last century has proved neither stable nor resilient, becoming increasingly vulnerable to the effects of ecological deterioration and an ever more commodified environment. Our environment has become ever more commodified, ever more the subject of short-term investment, income generation, and resale, rather than of lifelong dwelling or long-term city making (Benedikt, 1999).1 There is no need to argue vulnerability of cities in the region to understand the necessity to build resilience in all components and dimensions. The challenges that built environment is facing every day are effects of changes caused by climate change, environmental degradation, and population growth. This challenges can be overcome only by creating the building and urban resilience, developing architectural research practice and working on live projects.

\footnotetext{
${ }^{1}$ Patricia Mainardi in The End of the Salon (New York: Cambridge University Press, 1993) provides an excellent analysis of the importance of economic and market considerations in accounting for the origins of Modernism in art-art, for better or worse, as commodity.
} 
Role of the architects in creating building and urban resilience

\section{What is the resilience?}

The term resilience derives from different fields of science.

Many definitions and interpretations of resilience exist across multiple disciplines making it a difficult concept to quantify, evaluate, and gain clarity for what it means and how it applies to different industries (Hassler, U. and Kohler, N., 2014.)

In the psychology, resilience means the ability of patients to recover from stress or depression.

Resilience, as it was developed in systems thinking is "the ability [of a system] to cope with change". (Wieland, A. \& Wallenburg, C.M. , 2013)

The word resilience, invoked as a universal remedy in the recent economic crises and interpreted in sociology as the art of mediation in conflicts and thus as social resilience in situations characterized by difficult challenges, is now held in high regard in the field of architecture, city planning and landscape design too, having become one of the prime objectives in operations carried out following dramatic natural events, in particular those produced by the action of water. (Nicolin, 2014)

Resilience is a design objective for buildings and infrastructure. It is the ability to absorb or avoid damage without suffering complete failure. ${ }^{234}$

Recently, it has become a key concept in contemporary urbanism in the context of environmental, economic, and social crisis. However, resilience is mostly addressed in environmental and technical terms and often disregards social and cultural implications (Goldstein, 2011). Resilience deals with the ability of systems to adapt under change; thus, it also offers potential to rethink assumptions and build new systems (Folke, C.; Carpenter, S.R.; Brian Walker; Scheffer, M.; Chapin, T.; Rockström, J., 2010;) "Resilient" construction ensures that a structure will be more resistant to damage caused by hazards that destroy buildings in disasters, including fire, windstorms, earthquakes and flooding.

\section{What is the Architectural Resilience?}

Architectural resilience is strongly related to the definition stated by material engineers as the capability of certain materials to recover from stress and adapt to sudden inputs (Addington, M. and D. Schodek, 2005). Climate conditions figure as important concerns for architectural resilience. Concrete is the main construction material in Kosovo and region, which is not proven as the most resilient material during earthquakes.

\section{What is Urban Resilience?}

Urban Resilience is the ability of communities, cities, institutions, businesses, and systems within a city to survive, adapt, and grow. Urban Resilience is defined as "Capability to prepare for, respond to, and recover from significant multi-hazard threats with minimum damage to public safety and health,

\footnotetext{
2"Motivating business to design a more resilient nation, one building at a time" news release by Scandia National Laboratories July 23, 2013

${ }^{3}$ Resilience certification for commercial buildings: a study of stakeholder perspectives" Environment Systems and Decisions June 2013, Volume 33, Issue 2, pp 184-194 Barbara J. Jennings, Eric D. Vugrin, and Deborah K. Belasich

${ }^{4}$ Herrera, Manuel; Abraham, Edo; Stoianov, Ivan (2016-02-13). "A Graph-Theoretic Framework for Assessing the Resilience of Sectorised Water Distribution Networks". Water Resources Management: 1-15. doi:10.1007/s11269-016-1245-6. ISSN 0920-4741
} 
the economy, and security" (Wilbanks, 2007). As cities continue to grow and grapple with uncertainties and challenges like climate change, urban resilience has become an increasingly favored concept (Carmin, J., Nadkarni, N., \& Rhie, C., 2012); (Leichenko, 2011).

Multi-hazard threats come from different uncertainties and challenges experienced as chronic stresses more related to the social component or acute shocks more related to spatial and environmental component (Figure 1). Stresses weaken the built environment of a city on a daily or cyclical basis. Elements of chronic stresses are high unemployment, inefficient public transportation system, endemic violence, and chronic food and water shortages. Acute shocks are sudden, sharp events that threaten a city. In this events are categorized: earthquakes, floods, disease outbreaks, and terrorist attacks.

\section{Research context and trends}

Understanding context, trends, components and dimensions of resilience assessed define which building and urban resilience strategy to be applied. Analyzing past and today concepts it is clear that trends are going toward process understanding of the resilience.

\section{Paradigm shift}

Today, architects are moving from the concept of build environment as a product and focusing on process. They know that more than just contributing in spatial and environmental components by designing, spatial planning and environmental management, they can contribute to the social component by taking responsibilities in process of making communities more resilient. This is clear trend and tendency for the paradigm shift and fundamental change in architects and society's view of how to react to climate change, disasters and intentional attacks - wars.

There is not enough to assess and response by providing building safety assessments, and to disaster recovery through shelter design and urban development. Today is the need for assisting in the process of planning and achieving resilience through problem diagnosis, risk communication, and community outreach.

We can see more and more architects in the role of mediators, community builders, designers for reuse of build environment and active design practitioners.

\section{Building resilience}

Building resilience concept is emerging today's architectural practice, which is now challenged to design build environment that will first shape and then sustain a dramatically different and uncertain future. This concept has components to define and organize dimensions of buildings as adaptive systems across physical and time scales as the outcome, as well as a practical guide to organizing design decisions and strategies that lead to specific solutions of a process. Build environment has to be evaluated, designed and recovered in most important properties along the specific dimensions of protection, repair cost, and recovery.

Architects and building owners can implement some practical steps to create a resilience together with design professionals by: 
Role of the architects in creating building and urban resilience

-Creating an inventory of building assets and use experienced engineering professionals to employ a building rating system to rate the most important properties along the dimensions of safety, repair cost and recovery.

-Rank buildings according to their performance and identify which ones are contributing most to overall risk.

-Aggregate the portfolio to estimate expected casualties, damage costs and business interruption losses in a disaster, or over a defined time frame such as 20 or 50 years.

-Perform cost-benefit studies to best allocate resources to mitigation, risk transfer and event response/recovery planning.

-Use building ratings to help make decisions about real estate purchases or leases.

-To identify, those buildings that are most in need of catastrophe insurance and those that can retain less or forego coverage.

-To establish internal company design guidelines to ensure that most important assets will perform in an adequate manner with their value.

\section{City resilience}

Architects are contributing to city resilience. Generally, city resilience needs to be assessed, planned and eventually (after disasters) recovered based on social, spatial and environmental components and their dimensions. 
Book of Proceedings

International Conference on Architecture and Spatial Planning

\section{Social dimensions}

Increasing and improving social network, leadership and support systems.

Providing support to people during and after disaster.

Conducting post-event learning to improve.

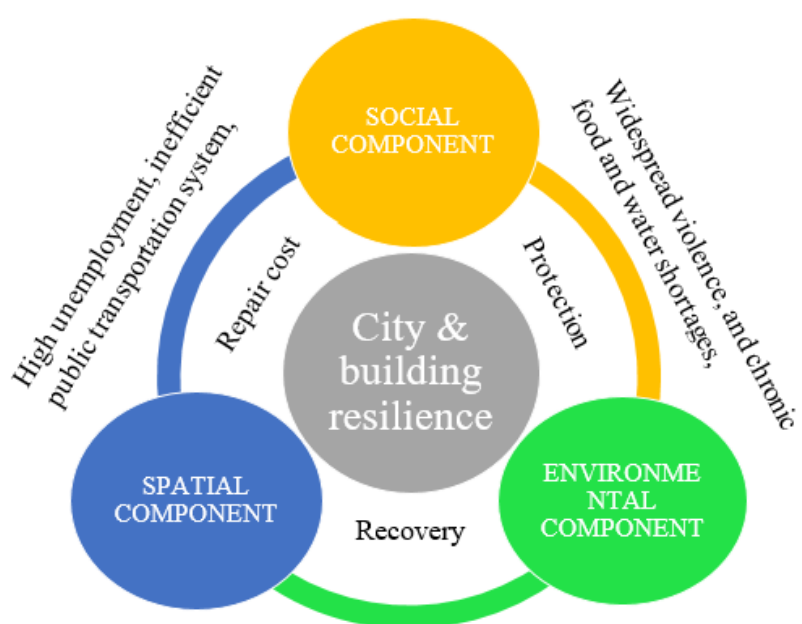

Earthquakes, floods, disease

outbreaks and terrorist attacks.

Spatial dimension

Analyzing vulnerability and resilience from spatial perspective

Understanding how location, spatial arrangement, spatial interactions and context relate to the resilience.

Creating build environment performance ratings based on detailed engineering evaluations of structures using technical standards.

\section{Environmental dimensions}

Developing an integrated environmental monitoring and prediction capability.

Accepting increasing risks.

Managing risks, optimizing resilience opportunities and minimizing vulnerability.

Figure 1 - Conceptual Framework with components, dimensions, events and elements for evaluating, designing (creating), and achieving built environment and city resilience

The conceptual framework in Figure 1 above is designed as the general concept that will serve professionals and all other actors. The conceptual framework will form the basis of a tool that should enable all interested in city resilience to convene around a common understanding of that idea and start to identify which components, dimensions, and indicators are most for making cities more resilient. The idea is to facilitate a process of engagement with and within cities that generates dialogue and deeper understanding. Understanding interrelations between all components, dimensions, elements of 
Role of the architects in creating building and urban resilience

chronic stresses and shocking events will lead to new ideas and opportunities to engage new actors in civil society, government, and business on identifying what makes a specific city resilient. Hopefully, in the future, this concept will help every city to develop specific city resilience index with specific indicators, sub-indicators and variables in different categories.

\section{Social component}

Elements of chronic stresses related to high unemployment, inefficient public transportation system, and endemic violence have to analyzed, assessed and treated with other components and all social dimensions listed below:

- Increasing and improving social network, leadership and support systems.

- $\quad$ Providing support to people during and after the disaster.

- $\quad$ Conducting post-event learning to improve.

\section{Spatial component}

Elements that threaten space in the city as an acute shock more related to spatial and environmental component have to analyzed, assessed and treated with other components and all spatial dimensions listed below:

- Analyzing vulnerability and resilience from spatial perspective

- Understanding how location, spatial arrangement, spatial interactions and context relate to the resilience.

- Creating build environment performance ratings based on detailed engineering evaluations of structures using technical standards.

\section{Environmental component}

Events that threaten a city environment as an acute shock more related to environmental component have to analyzed, assessed and treated with other components and all environmental dimensions listed below:

- Developing an integrated environmental monitoring and prediction capability.

- Accepting increasing risks.

- Managing risks, optimizing resilience opportunities and minimizing vulnerability.

\section{Suggestions}

For creating the specific building and urban resilience architects have to define and quantify solutions for the identified risks. Specified resilience is resilience of a specific dimension of a system to a specific shock. It is important to have integrated data infrastructure for all components and dimensions of the system. Focus on the resilience of one part the system can come at the cost of other parts of the system. The balance between all dimensions of resilience is important. When designing and planning resilience strategies architects suggest identified principles of innovation, foresight, adaptive multi-layered governance, the effective partnership among all actors involved in the resilient city creating. 
In national level, there is the need for including building and urban resilience in the unified national building code that is in the process of public discussion.

Understanding and promoting of conceptual framework as well as well as including building and urban resilience in unified national building code will be the first steps toward resilient city system that is: capable of accommodating the natural and constant increasing uncertainty and change in today's world; very well considered, constructed and managed physical assets, so that they can survive the impacts of hazard events without significant damage or loss of function; able to accommodate disruption, extreme pressures or surges in demand with extra capacity purposely created within systems; able to change, evolve and adapt in response to changing circumstances; able to rapidly find different ways for peoples and institutions to achieve their goals or meet their needs during a shock or when under stress; in broad consultation and engagement of communities, including the most vulnerable groups; integrated and aligned between city systems that promote consistency in decision-making and ensure that all investments are mutually supportive to a common outcome.

\section{Conclusions}

Architects know both the value and natural limits of architecture and planning. We don't know all the needs of architecture in the cities after stresses and shocks in the future, but we can improve architecture in the cities in the present and plan their resilient designs in the future. Therefore there is urgent need to expand architect's role and involvement in process of engagement with and within cities and contribute to building more resilient. This mean that we as architects have to assess existing social, spatial and environmental conditions from resilience perspective based on identified principles and in same time improve existing and future architectural designs and spatial planning (buildings and technical infrastructure) that will make the basement for resilient community and city.

\section{References}

1. Addington, M. and D. Schodek. (2005). Smart Materials and Technologies for the architecture and design professions,. Elsevier Architectural Press, Oxford, UK,, p. 2-4, 103-108.

2. Benedikt, M. (1999). Less for Less Yet: Architecture's Value in the Marketplace. Harvard Design Magazine.

3. Carmin, J., Nadkarni, N., \& Rhie, C. (2012). Progress and challenges in urban climate adaptation planning: Results of a global survey. Massachusetts: Cambridge, MA, USA. http://web.mit.edu/jcarmin/www/urbanadapt/Urban Adaptation Report FINAL.

4. Folke, C.; Carpenter, S.R.; Brian Walker; Scheffer, M.; Chapin, T.; Rockström, J. (2010;, 4 Volume 15,). Resilience thinking: Integrating Resilience, Adaptability and Transformability. Ecology and Society, . Ecology and Society,, p. 20.

5. Goldstein, B. E. (2011). Collaborative Resilience: Moving Through Crisis to Opportunity. Cambridge, MA:: MIT Press,.

6. Hassler, U. and Kohler, N. (2014.). Resilience in the built environment. Building Research \& Information. 42 (2), 119-129. 
Role of the architects in creating building and urban resilience

7. Leichenko, R. (2011). Climate change and urban resilience. Current Opinion in Environmental Sustainability, 3(3), http://dx.doi.org/10.1016/j.cosust.2010.12.014Lhomme,, 164-168. .

8. Nicolin, P. (2014). The Properties of Resilience. Lotus. 155, 52-57.

9. Wieland, A. \& Wallenburg, C.M. . (2013). The Influence of Relational Competencies on Supply Chain Resilience. A Relational View. International Journal of Physical Distribution \& Logistics Management, Vol. 43, No. 4, 300-320.

10. Wilbanks, T. (2007). "The Research Component of the Community and Regional Resilience Initiative (CARRI)". Presentation at the Natural Hazards Center, University of ColoradoBoulder. 